\title{
Cranial and spinal meningiomas in a pair of identical twin boys
}

\author{
C. B. SEDZIMIR, A. K. FRAZER, AND J. R. ROBERTS \\ From the Regional Department of Medical and Surgical Neurology, Walton Hospital, \\ and from The Department of Paediatric Neurology, Alder Hey Hospital, Liverpool
}

SUMMARY A unique set of identical twin boys with spinal and intracranial meningiomas is described. Three distinct spinal tumours and one intracranial one were removed surgically. One intracranial meningioma has been symptomless, so far. The red cell and leucocyte groups of the in two patients were found to be identical, and the probability of their being monozygous was estimat- $\vec{\circ}$ ed from these data as being 0.932 (Appendix).

There has been no report in the literature of twins with either intracranial or spinal meningiomas. In children and adolescents intracranial meningiomas are very rare and those within the spinal canal are only slightly less so. In twin David, the spinal meningioma became symptomatic at the age of 8 years. In twin Ian, two spinal meningiomas, separated by a distance of $25 \mathrm{~cm}$, produced symptoms at the age of 13 years. In the same boy an intracranial meningioma was removed $2 \frac{1}{2}$ months earlier, while twin David is known to have a symptomless intracranial meningioma which may have been present for three years. Despite the multiplicity of tumours, each of them evidently arose from a distinct nidus. There are no stigmata and no hereditary background to suggest a genetically transmitted condition of meningiomatosis as a variant of Von Recklinghausen's syndrome. Finally, there is no possibility of any of these tumours arising as a seedling transported by the cerebrospinal fluid circulation.

\section{CASE REPORTS}

The twin boys David and Ian were born on 1 July 1958. They lived in another part of the country until October 1967, when they moved to the Liverpool region.

The family history was unremarkable. The twins' paternal grandfather died at the age of 69 years of 'cardiac condition'. The grandmother is alive at the age of 68 years. The twins have one paternal aunt who emigrated many years ago to Canada where she had twin boys who died within days after birth.

The boys' maternal grandfather is alive and welto aged 68 years; the grandmother parted from hes husband and the twins' mother knows absolutel $\mathbb{S}_{\infty}$ nothing about her.

The mother and father of the twins and the thir $\frac{0}{4}$ child, a boy aged 7 years, are well and have no suffered from any severe illness.

SuMmary of Clinical DeTaILs Twin David Cases number 24342/67 (Fig. 1) He was one of identical twins born after a normal pregnancy and weighed

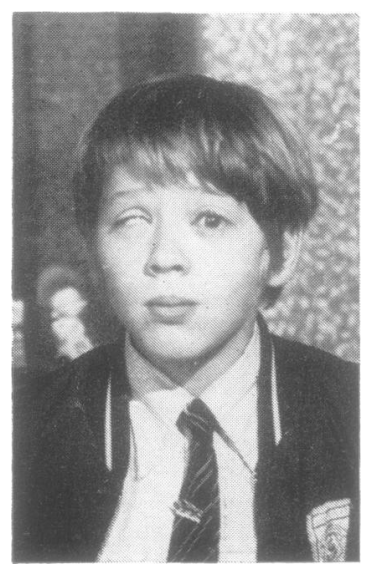

FIG. 1. Twin David. Born 1 July 1958. Photographed in November 1971. Note condition of eyes. 
$1.82 \mathrm{~kg}(4 \mathrm{lb})$ at birth. He developed normally, parallel to his twin brother Ian, except that he was found to have a congenital cataract when at the age of 16 months he developed a squint of the right eye. According to the mother, an ophthalmologist remarked that the boy's left eye was also abnormal.

In 1965, it was stated that the right eye was 'useless' because of a posterior polar congenital cataract and divergent squint. Some operative treatment on this eye was performed. The left eye was proptosed and ophthalmoplegic.

In 1966 there was a further operation on the right eye and, later in the same year, he had an arrow injury of the left eye needing an emergency operation, after which the visual acuity was 6/12. In 1967, the visual acuity in the right eye was hand movements only, but the left eye recovered to visual acuity of $6 / 6$. The proptosis and ophthalmoplegia remained unaltered (Fig. 1).

In the summer of 1966 at the age of 8 years, he developed 'abnormality of gait'. There was no papilloedema, and there was no abnormality of the upper limbs. In the lower limbs, slight spasticity was found in both legs with bilaterally increased tendon reflexes and extensor plantar responses. It was also remarked that he had marked bilateral 'claw feet'.

In May 1967 bilateral carotid angiography and air encephalography were performed elsewhere and were normal. In November 1967 the boy was referred to our Department. At that time the cranial nerves were normal except for the aforementioned congenital condition, and there were no neurological signs in the upper limbs. There was an almost complete spastic paraplegia. Sensation to pin prick was grossly depressed from D7 to S2 dermatomes bilaterally, with some sparing in S2-5 dermatomes. The bladder was distended but the patient could empty it reasonably well with some effort.

Vibration sense was depressed below the knees and joint position sense was lost in the toes. There was some depression of touch sensibility as well. Reflexes were clonic at both knees and ankles with bilateral extensor plantar responses. The lower abdominal reflexes were absent. Marked clawing of both feet was noted.

A diagnosis of mid-dorsal spinal tumour was made and myelography was undertaken. In view of the condition of the left eye, angiography with orbital views was also repeated in December 1967. No abnormality was noted in the skull. Left carotid angiography with special orbital views showed no abnormality. Lumbar myelography demonstrated complete obstruction at the level of D11 vertebral body and atrophy of pedicles of D10 vertebra.

Laminectomy of dorsal 10,11 , and 12 vertebrae was performed by Mr. A. G. MacIntyre. A menin- gioma situated in front and to the left of the dorsal spinal cord was totally resected.

The recovery of motor and sensory paraplegia was slow but he eventually returned to normal school and is excused only from physical training and competitive games. He does, however, play foot-

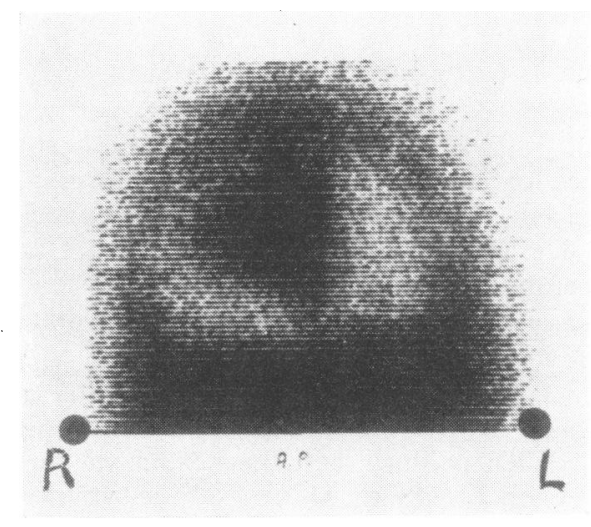

(a)

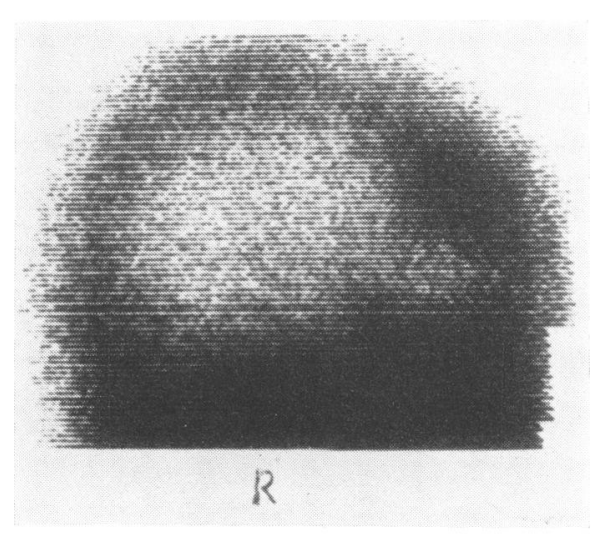

(b)

FIG. 2. David's brain scan, right lateral and axial. Evidence of meningioma.

ball with friends and runs fast and well despite the residual spasticity and some orthopaedic operations which were performed on the right tendo Achilles and right foot.

In October 1971, because of his twin brother's illness, he was examined by one of us by special arrangement. No change in cranial nerves or of the 
condition of the eyes was noted. The visual acuity in the left eye was $6 / 6$ and N8 corrected. Hand movements were appreciated vaguely by the right eye. There was no papilloedema. Upper limbs were normal. Trunk and lower limbs revealed slight spasticity, right more than left. There was shortening of the tendo Achilles on the right despite operative treatment. Motor power was good in all groups of muscles. There was anaesthesia in the left dorsal 8 and 9 spinal root distributions. Otherwise, sensation to pin prick, temperature, vibration, and joint position as well as touch were normal throughout.

Skull radiographs in November 1971 showed evidence of right frontal enostosis. There was a Klippel-Feil anomaly with rather wide cervical canal. The dorsal spine showed evidence of an old laminectomy but no other change. A brain scan showed evidence of a large right frontal falx meningioma (Fig. 2).

Summary (April 1972) There was a slight neurological deficit in both legs, the residue of the cord compression at D8 to 11 in 1967, a symptomless right frontal falx meningioma, and congenital ophthalmological conditions of both eyes.

SUMMARY OF CliniCAL DeTAILS Twin Ian Case no. 33866/72 (Fig. 3) Early development was normal. There were no disabilities and he was a good scholar, good at games and physical exercises. In May 1970 he developed painful neck stiffness after a game of badminton. This settled in a few days after wearing

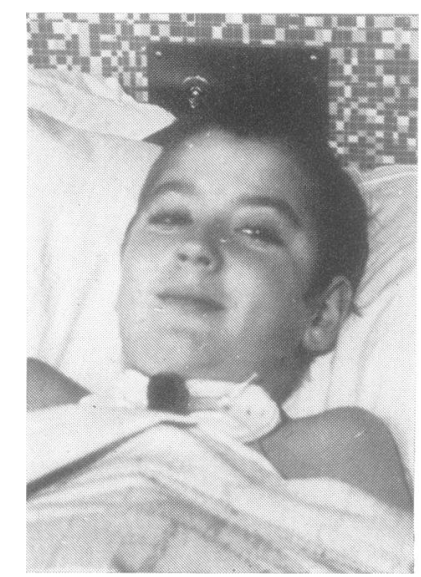

FIG. 3. Twin Ian photographed in November 1971. Born 1 July 1958. Tetraplegic. Tracheostomy. a cervical collar. In June 1971 he had more severe pain, mainly left sided, and in a few days he had 'a fixed' painful torticollis. He woke up one morning with paresis of the left arm and leg. He was admitted to a peripheral hospital and referred promptly to our Department with a diagnosis of 'cerebral angioma with subarachnoid haemorrhage'.

On examination on 1 July 1971 (his 13th birthday) he admitted to headaches for a few months. Cranial nerves showed no abnormality and there was no papilloedema. There was left-sided hemiparesis with increased tendon reflexes and bilaterally extensor plantar responses. It was also found that vibration sense and joint position sense were depressed in the left upper and lower limbs.

Radiographs of the skull showed changes in the region of the pituitary fossa consistent with longstanding raised intracranial pressure and sclerosis in the region of the tuberculum sellae and adjacent bony structures. Cervical spine radiography showed considerable widening of the spinal canal throughout the upper cervical segments consistent with an expanding process in this region.

No abnormality was demonstrated on lefe vertebral angiography but right carotid angiographyo showed a marked elevation and backward displace $-\frac{\mathbb{2}}{2}$ 음 ment of the anterior cerebral arteries and of theo proximal part of the pericallosal arteries. In addition $\_\subseteq$ on the lateral projection, the ophthalmic artery waso very large. These appearances were consistent with the presence of a meningioma of the tuberculumb sellae (Fig. 4).

A diagnosis of a large central and right-sided anterior basal meningioma was made. The probable origin was the tuberculum sellae and the tumour appeared to be invading the bone in the region of the posterior ethmoidal cells. It was decided to operate on this tumour and leave further investigations of the probable cervical tumour to a later date, depending on the results and findings of the cranial surgery.

Through a bifrontal flap, and after anterior right frontal lobectomy, an enormous meningioma was removed piece-meal at operation on 6 July 1971. It appeared to invade the posterior ethmoidal cells and surrounding bone on both sides and extended as far as the right olfactory groove. The affected bone of the anterior fossa was gouged away, heavily diathermied, waxed, and covered by a graft of temporal fascia.

Postoperative progress was very stormy but eventually he began to recover power in the left limbs until the end of July. He then developed weakness of the right upper limb and gradually, by the end of August, he became entirely tetraplegic. There was in addition a loss to pin-prick sensation bi- 


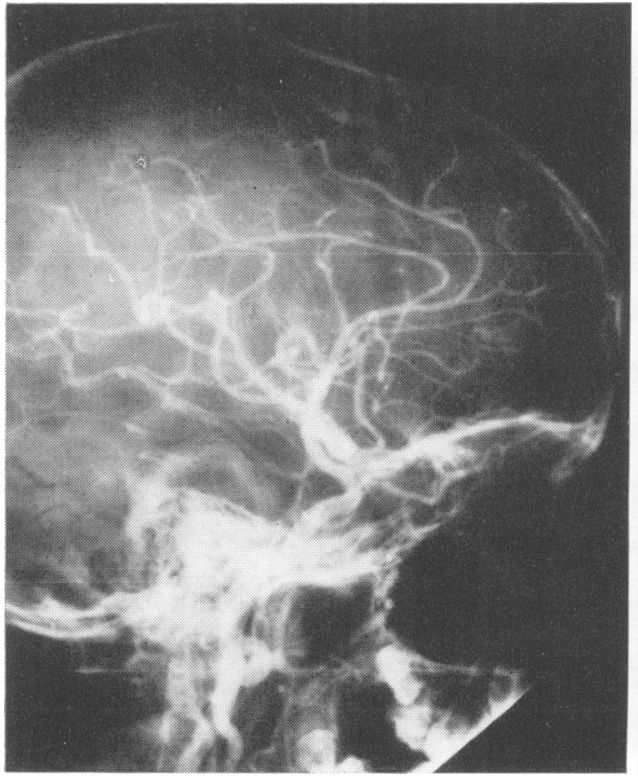

(a)

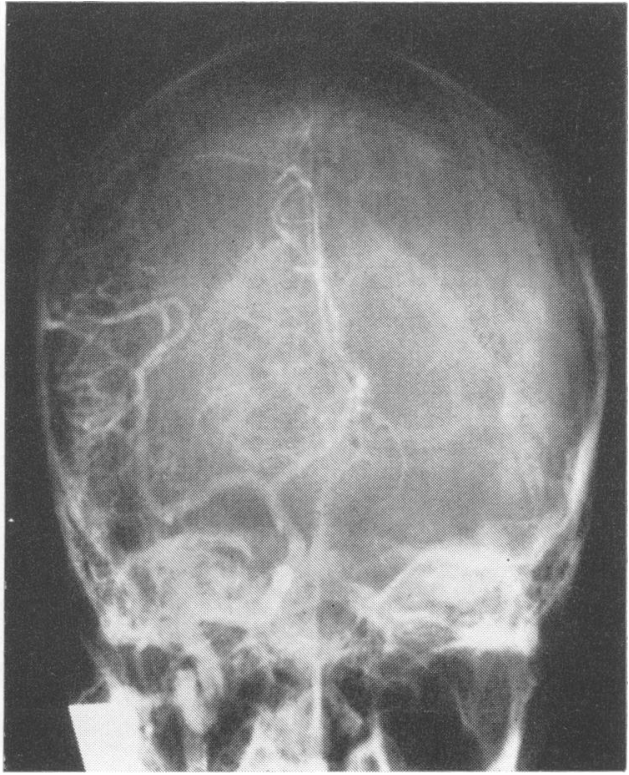

(b)

FIG. 4. Ian's right carotid angiogram. Lateral and axial projections. Basal frontal meningioma confirmed.

laterally below $\mathrm{C} 4$ dermatome. Vibration and joint position sense were lost in both lower limbs and depressed in the hands and fingers. His breathing was entirely diaphragmatic. He could still empty his bladder satisfactorily and some bladder sensation was preserved.

In addition to the previously suspected upper cervical meningioma, lumbar myelography disclosed another tumour. The contrast medium was completely held up at the level of the body of D11 vertebra by an intrathecal extramedullary lesion displacing the cord from left to right.

The patient was fully conscious and despite his plight his morale was excellent.

Cervical laminectomy of $\mathrm{Cl}$ to $\mathrm{C} 6$ was performed on 24 August with removal of the posterior border of the foramen magnum. A large meningioma was resected. It was situated anterolaterally to the cord, which was displaced posteriorly and to the right. The employment of bipolar coagulation and of the operating microscope greatly assisted the dissection and safeguarded the vasculature of the spinal cord. The attachment of the meningioma to the dura mater was over a very small area.

Under the same anaesthetic, the patient was repositioned and laminectomy of dorsal 9-12 vertebrae was performed. Another meningioma was found, also anterolaterally to the cord. The tumour was removed completely but the area of attachment here was rather broad. It was thoroughly coagulated.

Tracheostomy was performed at the end of the two laminectomies and the patient lived depending entirely on the respirator until the beginning of December 1971 when he was gradually allowed to breathe on his own during the day for short periods.

NEUROLOGICAL RECOVERY TO DATE (1 April 1972) His mental faculties are normal. He reads, watches television, follows 'his' football club and enjoys visits of members of his family. He is very well informed in current affairs of interest to a boy of his age. $\mathrm{He}$ is no longer on a respirator. Breathing is maintained by the diaphragm, but there is now some effective function of the intercostal muscles.

On the right side, all muscle groups involved in movements of the scapula, shoulder, elbow, wrist, and fingers are strength grade 4-5 except for deltoid (2) and triceps (3). The right hip and knee movements are grade $2-3$, all the remaining lower limit muscles are grade 1 , but extensors of the toes are 0 .

On the left side scapular movements are grade 3, shoulder 1 , biceps 1 ; there are no other movements 


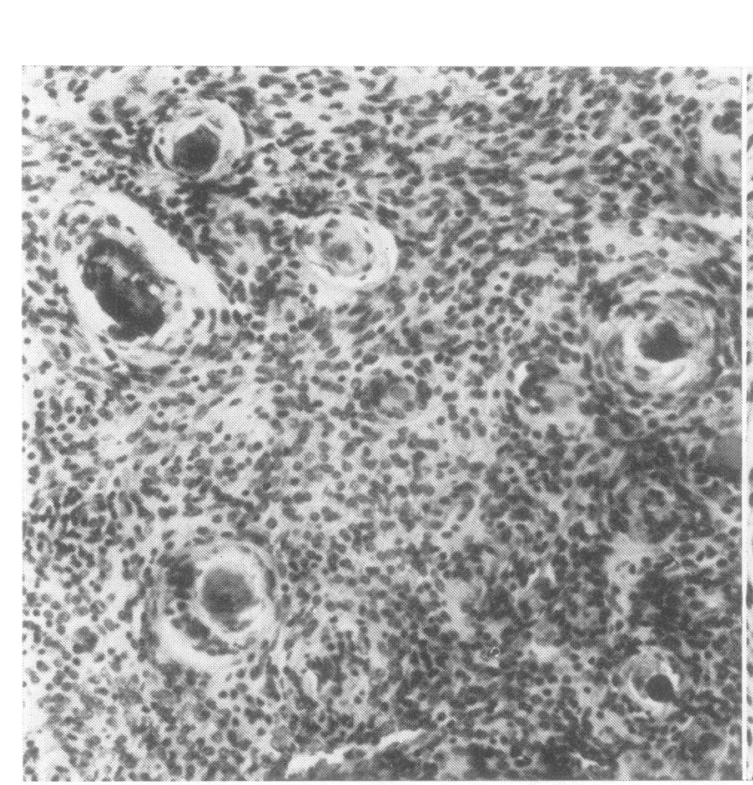

(a)

(b)

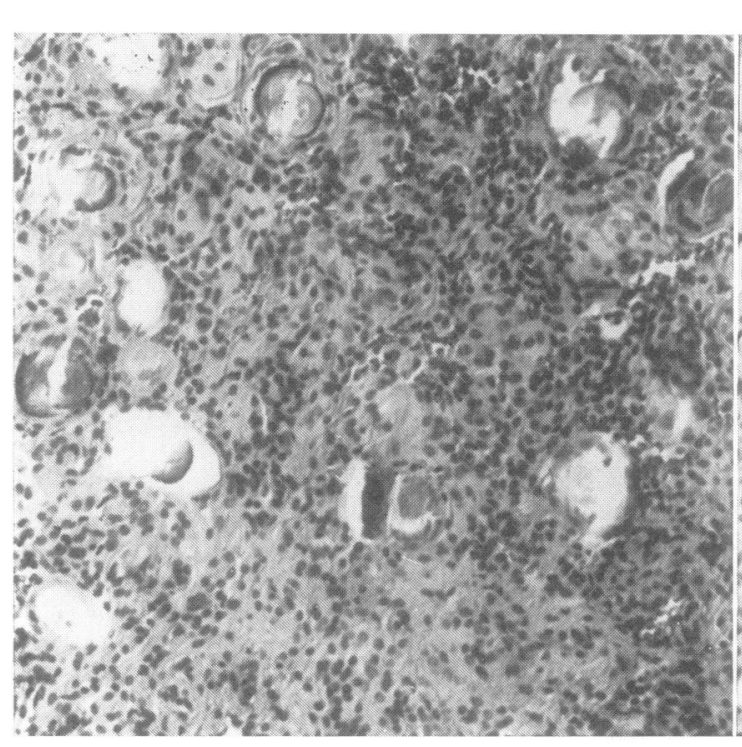

(c)

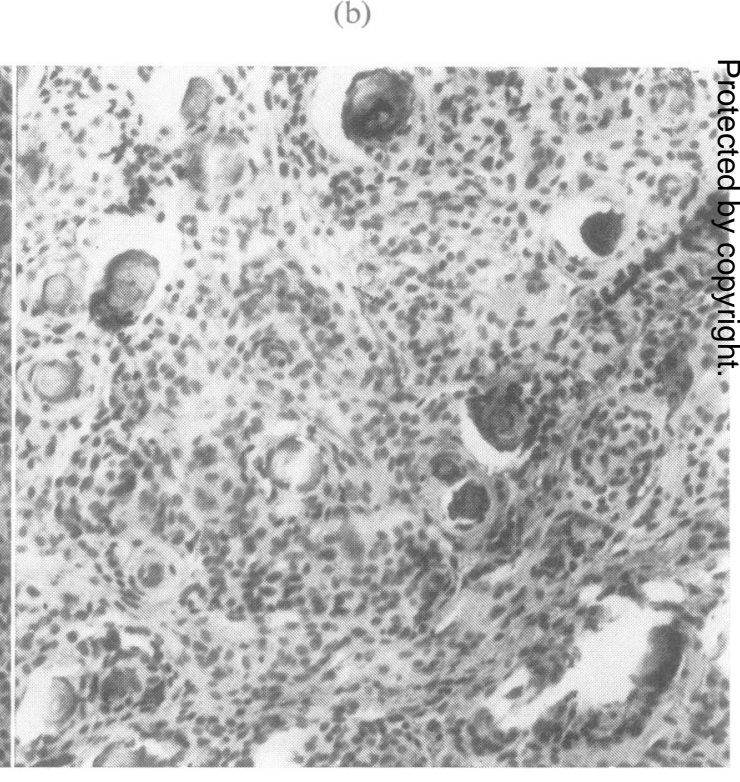

(d)

FIG. 5. (a) Twin David's dorsal meningioma, 1967. (b) Twin Ian's intracranial meningioma, 1971. (c) Ian's upper cervical meningioma, 1971. (d) Ian's dorsal meningioma, 1971.

at elbow or at the wrist. Flexors of the fingers are 2 , but no extension is present. The left hip movements are $1-2$; below the hip there is a complete paralysis of all muscle groups.

Pin-prick is appreciated all over the body, though depressed, as compared with the trigeminal area.
There is anaesthesia in the left $\mathrm{C} 2$ root distribution, 을 which was divided during the operation. Joint position sense is lost in both legs. The bladder is $N$ expressed by suprapubic pressure every two hours. $N$ He occasionally visits patients in the adjoining wards, N pushed around in a wheel-chair. 
SUMMARY OF HISTOLOGICAL FINDINGS Twin David The dorsal meningioma contained cellular syncytial and psammomatous areas. There were numerous calcispherites.

Twin Ian The frontal basal meningioma was very cellular with syncytial and psammomatous areas. Despite the cellularity, very few mitoses were seen. The upper cervical/foramen magnum meningioma and mid-dorsal meningioma showed outstandingly similar histological patterns in all fragments of syncytial and psammomatous type of meningioma with many calcispherites. There were no suggestions of sarcomatous change.

Dr. P. Buxton reviewed and compared the four tumours. Twin Ian's tumours were somewhat more cellular and twin David's tumour showed more calcification of psammomata and more calcispherites. Otherwise all these tumours were remarkably similar (Fig. 5).

\section{DISCUSSION}

Ten pairs of twins with central nervous system neoplasms have been reported in the literature. Nine of them were presented in a compact and informative table by Metzel (1963), and the tenth was reported by Fairburn and Urich in 1971. Four of the sets succumbed to cerebellar medulloblastomas, one to tumours exhibiting a mixture of oligodendroglial and astrocytic elements. Five sets had different types of tumours.

The pair of uniovular male twins described by Hope (1952) is of greatest interest to this discussion, being the only example of a meningioma (left sphenoidal wing) successfully excised at the age of 40 years, while the other twin died of glioblastoma multiforme at the age of 53 years.

Gaist and Piazza (1959) were the first to record a single meningioma in two siblings - a sister aged 39 and a brother aged 36 years at the time of the clinical presentation of the intracranial tumours. The female had a left frontal surface meningioma removed in 1954 and the male a right frontal parasaggital meningioma resected in 1955. The authors stressed that neither of these patients had any stigmata of Von Recklinghausen's disease and neither had a sign of other neoplasms or of recurrent neoplasia when reported on in 1959.

The problem of multiple meningiomas has recently been discussed by Zervas, Shintani, Kaller, and Berry (1970). The point at issue is that the definition set out by Cushing and Eisenhardt (1938) to distinguish, one assumes, between multiple meningiomas and meningiomatosis - that is, 'more than one meningioma and something less than a diffusion of them'appears somewhat artificial and in some cases, at least, difficult to ascertain.

In a series of 300 intracranial meningiomas treated in the Regional Department of Surgical Neurology, Liverpool, between 1950-71, there were four instances of these tumours at the age of $13,14,18$, and 19 years. The ratio of intracranial meningiomas in juveniles to intracranial meningiomas in adults is $1: 75$. In the same period of time there were only two in children, the presently described twins, out of 64 spinal meningiomas, a ratio of $1: 32$. The ratio of all intracranial meningiomas to all spinal meningiomas is $4 \cdot 6: 1$.

It is felt that the ratio of both intracranial and spinal meningiomas in juveniles as in adults is likely to be as precise as is ever practical when children and adults are treated by the same service - namely, a Neurological Surgical Service dealing with cranial and spinal neoplasms at all ages in a specific geographical regional board area of the National Health Service. The Liverpool Regional Departments for Medical and Surgical Neurology, in association with the Department of Paediatric Neurology fulfil as nearly as possible the criteria of a Regional Service, and, although the National Health Service allows the facility for inter-Regional transfer and treatment, it is felt that this faculty is rarely used in the North of England, whatever the situation in the South.

INTRACRANIAL JUVENILE MENINGIOMAS Cushing and Eisenhardt (1938) in a series of 313 meningiomas reported only six in the pre-adolescent group. Bailey, Buchanan, and Bucy (1939) reported two cases in a series of 100 intracranial tumours of infancy and childhood. Keith, Craig, and Kernohan (1949) noted three meningiomas in a series of 606 paediatric tumours. Cuneo and Rand (1955) reported two cases of meningiomas among 83 children with intracranial tumours. One of these, in an infant of 3 months, was already calcified. Garcia, Bengochea, Fuste, and Fernández Carrera (1956) reported a child aged 3 years with a small meningioma in the region of 
the left internal auditory meatus and stated that Markham, Fager, Horrax, and Poppen (1955) also had a boy aged 15 years with a meningioma in this region, while Petit-Dutaillis (1949) reported a child aged 9 years with a meningioma in the posterior fossa. All these three last mentioned cases were true psammomatous meningiomas. Paillas, Vigouroux, Piganiol, and Sedan (1957) reported 92 intracranial tumours in children of which only two were meningiomas. French (1959) found seven cases of meningiomas, one in a 6 month old baby, out of 273 paediatric tumours. Obrador (1960), in a series of 150 meningiomas, found eight under the age of 20 years. Taptas (1961) removed a suprachiasmal meningioma from a boy aged 2 years and, when the patient was aged 4, a left intraventricular meningioma was also successfully removed. Matson (1969) found three instances of meningioma in a series of 750 consecutive paediatric intracranial tumours. Mendiratta, Rosenblum, and Strobos (1967) removed a meningioma from a boy 6 months old. Klump and McDonald(1971) removed successfully a large frontal fibroblastic meningioma from a 3 year old boy in 1966 who was well when reviewed in 1969.

TRANSITIONAL LOCALIZATION Porras (1963) reported the removal of a meningioma situated in the foramen magnum from a child aged 8 years by upper cervical laminectomy combined with occipital craniectomy. This localization is somewhat similar to that found in our twin Ian.

SPINAL MENINGIOMAS It would appear that Eskridge and Freeman (1898) were the first to remove what was almost certainly a spinal meningioma from a boy aged 12 years which is, as Rand (1962) remarks, only 10 years after Horsley's (1888) first ever successful removal of a spinal thoracic tumour.

Hamby (1944) showed that of the five reported spinal meningiomas in children between 1933-42, three, all girls, aged 5, 5, and 11 years, had high cervical tumours. One of the 5-year-old girls came to necropsy after $2 \frac{1}{2}$ years of symptoms. This is, therefore, to the best of our knowledge, the youngest child reported with a meningioma of the spinal canal.

The remaining two were boys age 7 and 10 years, with meningiomas at the levels of D4-5 and D7 vertebrae respectively.

It is of great interest to note that Grant and Austin (1956) report as many as five spinal meningiomas among their 30 patients with spinal tumours under the age of 15 years. This is, indeed, an exceptionally high incidence from a single source, the highest we were able to find. We consider that the greatest value of Grant and Austin's paper is the statement that 'although they (children) seem to recover from paraparesis usually in a satisfactory manner, when there is a complete paraplegia the outcome is extremely grave. Thirteen of our (30) patients were completely paraplegic at the time of surgery-only one of these (13) children recovered some voluntary movement after surgery'. The gravity of the condition of progressive paraparesis (be it motor and/or sensory) and the urgency with which children (or adults) should be investigated and, when appropriate, treated surgically, must unfortunately be stressed as emphatically today as was necessary 16 years ago.

Svien (1954) in 41 patients with spinal tumours under the age of 15 years did not find a single example of a meningioma! Haft, Ransohoff, an Carter (1959), in a series of 30 children had onl\$ one case of meningioma. They stated that the ratio of adult spinal meningioma to sping meningiomas in children is $6: 1$. Rand and Rand (1960) found two spinal meningiomas among 64 intraspinal neoplasms of childhood.

Matson (1965) reported a series of 134 consecutive primary spinal tumours, three of which were meningiomas. Banna and Gryspeerdt (1971) in their series of 32 children under 16 years of age, found no instance of a meningioma.

\section{DISCUSSION OF THE CASES PRESENTED}

In the case of twin David the onset of symptoms referable to the spinal tumour coincided approximately with his 8th birthday in 1966. The diagnosis was made and a dorsal (D8-11) meningioma was removed about 16 months 웅 later, in December 1967.

There was radiological proof that in 1966 and in 1967 he did not have an intracranial tumour, N as evidenced by negative cerebral angiography and pneumoencephalography elsewhere. Therefore the question of a possible 'seeding' of the 
neoplasm from the intracranial to the lower dorsal spinal cord does not arise.

In November 1971, after the removal of an intracranial meningioma from his brother Ian, the parents were asked to agree to a brain-scan on David, as well as further radiographs of the skull and spine, in order to complete all available investigations. It was only because of this that the presence of a right frontal falx meningioma was discovered.

This tumour is still (April 1972) completely symptomless, and there are no neurological signs whatsoever to betray its presence, despite a very thorough neurological examination by one examiner who was aware of the presence of the intracranial tumour, and another who did not know that it existed. The tumour is obviously of recent origin and must have arisen from its own nidus.

In the case of twin Ian, the basal, frontal, intracranial meningioma and the upper cervical tumour were both large and presented as anatomically rather distant, independent entities, at about the same time. Quite likely the mid-dorsal meningioma was also already present, although too small to contribute to the neurological picture.

The 'seeding' theory advanced to explain some cases of multiple meningiomas does not apply in these twins and, in any case, this hypothesis appears more valid when applied to explain the occurrence of spinal ependymomas after a removal of an intracranial lesion.

In view of the continuous and promising neurological recovery of twin Ian after the removal of the three meningiomas in 1971, and the excellent recovery of twin David after the removal of the dorsal meningioma, it is suggested that the saga of these twins may be longer and happier than we at first dared to hope.

There is no doubt that one day, months or years hence, the intracranial tumour of twin David will become active and will require a craniotomy. There is always a possibility that the intracranial tumour of twin Ian may recur, in which case radical surgery would no longer be practical.

It is felt that, whatever the final detailed outcome in these boys, there will be no further light thrown on the basic problem of this unique 'freak' mutation.
We are greatly indebted to Dr. J. Woodrow and Mr. W. T. Donohoe of the Nuffield Unit of Medical Genetics, Department of Medicine, University of Liverpool, for the meticulous and extensive studies, the results of which are set out in the Appendix. Dr. P. Buxton not only reported on the histological material but greatly helped with the clinical photography and the setting out of all illustrations. Dr. J. V. Occleshaw kindly reported on all the radiological investigations carried out in the Regional Department of Neuro-Radiology of Liverpool.

ADDENDUM Ian died on 17 July 1972. There was no necropsy.

\section{REFERENCES}

Bailey, P., Buchanan, D. N., and Bucy, P. C. (1939). Intracranial Tumors of Infancy and Childhood. University of Chicago Press: Chicago, Ill.

Banna, M., and Gryspeerdt, G. L. (1971). Intraspinal tumours in children (excluding dysraphism). Clinical Radiology, 22, 17-32.

Cuneo, H. M., and Rand, C. W. (1952). Brain Tumors of Childhood. Thomas: Springfield, Ill.

Cushing, H. W., and Eisenhardt, L. (1938). Meningiomas. Thomas: Springfield, Ill.

Eskridge, T. J., and Freeman, L. (1898). Intradural spinal tumor opposite the body of the fourth dorsal vertebra; complete paralysis of the parts below the lesion; operation; recovery, with ability to walk without assistance within three months. Philadelphia Medical Journal, 2, 1236-1243.

Fairburn, B., and Urich, H. (1971). Malignant gliomas in identical twins. Journal of Neurology, Neurosurgery, and Psychiatry, 34, 718-722.

French, L. (1959). Tumors-intracranial and cranial. In Pediatric Neurosurgery, pp. 224-350. Edited by I. J. Jackson and R. K. Thompson. Thomas: Springfield, Ill.

Gaist, G., and Piazza, G. (1959). Meningiomas in two members of the same family (with no evidence of neurofibromatosis). Journal of Neurosurgery, 16, 110-113.

García Bengochea, F., Fusté, R., and Fernández Carrera, J. C. (1956). Meningioma of the internal auditory meatus in a child 3 years old. Journal of Neurosurgery, 13, 215-218.

Grant, F. C., and Austin, G. M. (1956). The diagnosis, treatment, and prognosis of tumors affecting the spinal cord in children. Journal of Neurosurgery, 13, 535-545.

Haft, H., Ransohoff, J., and Carter, S. (1959). Spinal cord tumors in children. Pediatrics, 23, 1152-1159.

Hamby, W. B. (1944). Tumors in the spinal canal in childhood. II. Analysis of the literature of a subsequent decade (1933-1942). Journal of Neuropathology and Experimental Neurology, 3, 397-412.

Hoppe, H.-J. (1952). Diskordantes Auftreten von Hirntumoren bei erbgleichen Zwillingen. Zentralblatt für Neurochirurgie, 12, 34-36.

Keith, H. M., Craig, W. McK., and Kernohan, J. W. (1949). Brain tumors in children. Pediatrics, 3, 839-844.

Klump, T. E., and McDonald, J. V. (1971). Successful removal of a large meningioma in a three-year-old boy. Journal of Neurosurgery, 34, 92-94.

Markham, J. W., Fager, C. A., Horrax, G., and Poppen, J. L. (1955). Meningiomas of the posterior fossa. Their diagnosis, clinical features, and surgical treatment. Archives of Neurology and Psychiatry, 74, 163-170. 
Matson, D. D. (1969). Neurosurgery of Infancy and Childhood. 2nd edn. Thomas: Springfield, Ill.

Mendiratta, S. S., Rosenblum, J. A., and Strobos, R. J. (1967). Congenital meningioma. Neurology (Minneapolis), 17, 914-918.

Metzel, E. (1963). Über die familiär gehäuften Gliome. Archiv für Psychiatrie und Nervenkrankheiten, 204, 537-555.

Obrador Alcalde, S. (1960). Reflexiones sobre una estadistica operatoria de 150 meningiomas intracraneales. Revista Clínica Española, 77, 99-107.

Paillas, J. E., Vigouroux, R., Piganiol, G., and Sedan, R. (1957). Les tumeurs supratentorielles de l'enfant. NeuroChirurgie, 3, 165-179.

Petit-Dutaillis, D., and Daum, S. (1949). Les méningiomes de la fosse postérieure. (Premier mémoire.) Revue Neurologique, 81, 557-572.

Porras, C. L. (1963). Meningioma in the foramen magnum in a boy aged 8 years. Journal of Neurosurgery, 20, 167-168.

Race, R. R., and Sanger, R. (1968). Blood Groups in Man, 5th edn. Blackwell Scientific Publications: Oxford.

Rand, R. W., and Rand, C. W. (1960). Intraspinal Tumors of Childhood. Thomas: Springfield, Ill.

Svien, H. J., Thelen, E. P., and Keith, H. M. (1954). Intraspinal tumors in children. Journal of the American Medical Association, 155, 959-961.

Taptas, J. N. (1961). Intracranial meningioma in a fourmonth-old infant simulating subdural haematoma. Journal of Neurosurgery, 18, 120-121.

Teng, P., and Papatheodorou, C. (1963). Suprachiasmal and intraventricular meningioma in a four-year-old child. Journal of Neurosurgery, 20, 174-176.
Zervas, N. T., Shintani, A., Kallar, B., and Berry, R. G.으 (1970). Multiple meningiomas occupying separate neur- $Z$ axial compartments. Case report. Journal of Neurosurgery, 33, 216-220.

\section{APPENDIX}

The red cells of the two patients and of their parents were typed with the following antisera: AntiA A ${ }_{1}$ B D C C E c e M N S s $P_{1}$ Fy $^{\mathrm{a}} \mathrm{Fy}^{\mathrm{b}} \mathrm{K} \mathrm{k} \mathrm{Jk}^{\mathrm{a}} \stackrel{\text {. }}{\Rightarrow}$ $\mathrm{Jk}^{\mathrm{b}} \mathbf{L u}^{\mathrm{a}} \mathbf{L u}^{\mathrm{b}}$. Samples of saliva were tested to deter-只 mine secretor status.

Both patients were group $\mathrm{O}$ rr Ms/Ms $P_{1} P_{2} \frac{\overline{\bar{N}}}{\bar{n}}$ $\mathrm{Fy}^{\mathrm{a}} \mathrm{Fy}^{\mathrm{b}} \mathrm{kk} \mathrm{Jk}^{\mathrm{a}} \mathrm{Jk}^{\mathrm{b}}$ and were non-secretors.

The data were analysed by the method described in Race and Sanger (1968) taking into account the ${ }^{\infty}$ parental blood groups. Only the Rh, MNSs and Jk. systems gave useful information. The probability of $\overrightarrow{\vec{H}}$ the twins being monozygous is 0.932 and of their ${ }_{\sigma}^{\omega}$ being dizygous is 0.068 .

In addition, the peripheral leucocytes of the twins were typed with 38 different antisera and both were HLA(27) and $4^{\text {b }}$. 